\title{
Matrix metalloproteinase activity in thoracic aortic aneurysms associated with bicuspid and tricuspid aortic valves
}

Jon Boyum, MD

Erika K. Fellinger, MD

Joseph D. Schmoker, MD

Lucy Trombley, MS

Kenneth McPartland, MD

Frank P. Ittleman, MD

Alan B. Howard, MS
From the Department of Surgery, Division of Cardiothoracic Surgery, Fletcher Allen Health Care and the University of Vermont, Burlington, Vt.

Read at the Twenty-ninth Annual Meeting of The Western Thoracic Surgical Association, Carlsbad, Calif, June 18-21, 2003.

Received for publication June 20, 2003; revisions requested Oct 22, 2003; accepted for publication Nov 4, 2003.

Address for reprints: Joseph D. Schmoker, MD, Division of Cardiothoracic Surgery/ Fletcher Allen Health Care, Fletcher 454, 111 Colchester Avenue, Burlington, VT, 05401(E-mail:joseph.schmoker@vtmednet. org).

J Thorac Cardiovasc Surg 2004;127:686-91 $0022-5223 / \$ 30.00$

Copyright $\odot 2004$ by The American Association for Thoracic Surgery

doi:10.1016/j.jtcvs.2003.11.049
Objective: Matrix metalloproteinases are endopeptidases that function in cell matrix turnover. Abnormal matrix metalloproteinase activity has been implicated in the formation of atherosclerotic abdominal aortic aneurysms. Recent studies suggest that abnormal matrix metalloproteinase activity may also be associated with the formation of atherosclerotic and nonatherosclerotic thoracic aortic aneurysms. Bicuspid aortic valves are associated with an intrinsic aortic pathology that predisposes to formation of proximal thoracic aneurysms while tricuspid aortic valves are not. The objective of this study was to compare the activities of matrix metalloproteinases and levels of their inhibitors in thoracic aneurysms of patients with bicuspid and tricuspid aortic valves.

Methods: Endogenous and total activity of matrix metalloproteinase-2 and matrix metalloproteinase-9 were measured in proximal nonatherosclerotic thoracic aortic aneurysms of 16 patients with bicuspid aortic valves and 12 patients with tricuspid aortic valves. Levels of tissue inhibitor metalloproteinase- 1 and -2 were also measured. Results were standardized to total protein $(\mathrm{mg})$.

Results: Total matrix metalloproteinase- 2 activity was greater in aneurysms associated with bicuspid valves when compared with those from tricuspid valves (43 \pm $11 \mathrm{ng} / \mathrm{mg}$ vs $14 \pm 2 \mathrm{ng} / \mathrm{mg}, P=.02$ ). Total matrix metalloproteinase- 9 activity was also greater in aneurysms associated with bicuspid aortic valves $(4.0 \pm 0.9$ vs 1.5 $\pm 0.3, P=.02$ ). There was no meaningful difference between groups in levels of tissue inhibitor-1 and -2 .

Conclusion: The increased activity of matrix metalloproteinases in the walls of aneurysms associated with bicuspid aortic valves may partly explain the predilection to aneurysm formation in these patients.

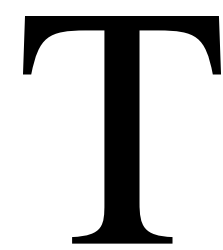

he proximal thoracic aorta of patients with bicuspid aortic valves is predisposed to dilatation and aneurysm formation. ${ }^{1-3}$ Many investigators have shown that these patients have intrinsic abnormalities in the structural integrity of their aortic walls. ${ }^{4-8}$ Abnormal elastic properties within the ascending aorta have been documented by echocardiography in young patients with bicuspid aortic valves. ${ }^{4}$ Prominent histologic findings in patients with bicuspid valves include alterations in the elastic lamellae within the media of the proximal thoracic aorta. Notably, there is an increase in elastin fragmentation, ${ }^{5,7}$ which occurs even in the absence of aneurysmal disease. ${ }^{6}$ 
Fragmentation of elastin also occurs in abdominal aortic aneurysms and is thought to be a key factor in aneurysm pathogenesis. Much recent attention has focused on matrix metalloproteinases as a cause of this structural degeneration leading to aneurysm formation. ${ }^{9}$ Matrix metalloproteinases are endopeptidases that are synthesized and secreted by the cellular components of the vessel wall and inflammatory cells. Metalloproteinases normally function in extracellular matrix turnover by degrading matrix proteins such as collagen, elastin, and proteoglycans. ${ }^{10}$ The walls of abdominal aortic aneurysms, however, are known to have an imbalance in this normal turnover mechanism such that matrix metalloproteinase activity is significantly higher in the walls of aneurysms than in controls. ${ }^{11,12}$ This is particularly true for matrix metalloproteinase- 9 , which is released by tissue macrophages associated with the inflammatory environment of the atherosclerotic plaque. ${ }^{11,13}$ This imbalance favors elastin fragmentation, which is thought to be the primary event in aneurysm formation. ${ }^{14}$

Recent evidence suggests that an alteration in matrix metalloproteinase activity also occurs in thoracic aortic aneurysms. ${ }^{15-17}$ A previous study found that matrix metalloproteinase-9 activity was elevated in thoracic aortic aneurysms of atherosclerotic etiology when compared with those of nonatherosclerotic etiology and age-matched controls. ${ }^{16}$ This current study sought to characterize the role of matrix metalloproteinases and their inhibitors in patients with nonatherosclerotic degenerative proximal thoracic aneurysms associated with bicuspid aortic valves.

\section{Materials and Methods Patients}

Samples of discarded aortic root and ascending aortic aneurysm tissue, taken from the anterior wall of the aneurysm adjacent to the sinotubular ridge, were collected from patients undergoing elective aortic reconstruction for proximal nonatherosclerotic thoracic aortic aneurysms at Fletcher Allen Health Care between December 1, 2000, and December 30, 2002. Patients with documented atherosclerotic changes within the aneurysm wall by either gross inspection or by histologic examination (hematoxylin and eosin staining) were excluded. By doing this, we sought to eliminate patients in whom the inflammatory infiltrate associated with an atherosclerotic plaque could be a major component of aneurysm formation. Atheroma contains an inflammatory infiltrate, including the tissue macrophage, which synthesize and secrete matrix metalloproteinase-9. ${ }^{18}$

Aortic specimens were collected from 28 patients with nonatherosclerotic, proximal thoracic aortic aneurysms. Sixteen patients had an associated bicuspid aortic valve and 12 patients had a tricuspid aortic valve. None of the patients had Marfan syndrome or aortic dissection.

The medical record of each patient was reviewed and the pertinent medical history was recorded. The study met with criteria set forth by the Institutional Review Board of this institution.

\section{Tissue Handling and Preparation}

The aortic tissue was immediately placed in a phosphate-buffered saline solution at $4^{\circ} \mathrm{C}$ and transported to the laboratory where it was snap-frozen in liquid nitrogen and stored at $-80^{\circ} \mathrm{C}$ until the time of preparation and analysis. Our operating room policy forbids the transport of liquid nitrogen within the operating room facility. At the time of analysis, tissue samples (0.15-0.4 $\mathrm{g}$ wet weight) were homogenized in $1 \mathrm{~mL}$ of $50 \mathrm{mmol} / \mathrm{L}$ Tris- $\mathrm{HCl}$ buffer ( $1.5 \mathrm{mmol} / \mathrm{L} \mathrm{NaCl}, 0.5 \mathrm{mmol} / \mathrm{L} \mathrm{CaCl}{ }_{2}, 1 \mu \mathrm{mol} / \mathrm{L} \mathrm{ZnCl}_{2}$, and $0.01 \%[\mathrm{v} / \mathrm{v}$ ] polyoxyethelene laurel ether [BRIJ 35; Biomedia Corporation, Foster City, Calif]) at $4^{\circ} \mathrm{C}, \mathrm{pH} 7.4$, and placed on ice. The homogenates were then spun at 8000 revolutions per minute (rpm) for 5 minutes and the supernatants from each sample were collected. The pellets were then resuspended in $1 \mathrm{~mL} 50 \mathrm{mmol} / \mathrm{L}$ Tris and a second homogenization was performed, followed by centrifugation at $8000 \mathrm{rpm}$ for 5 minutes. The combined supernatants from each sample were spun at $10,000 \mathrm{rpm}$ for 10 minutes and the final supernatant was collected and used for analysis. Total protein concentrations $(\mathrm{mg} / \mathrm{mL})$ were quantified in each final supernatant sample using a protein assay (BIO-RAD, Hercules, Calif).

The endogenous and total activity of matrix metalloproteinase- 2 and -9 was quantified in the supernatants by activity assays (MMP-2 and MMP-9 Biotrak Activity Assay System, Amersham Biosciences Corp, Piscataway, NJ). These activity assays are based on an antibody-capture technique that sequesters both the active and inactive forms of the metalloproteinase. Bound endogenously active metalloproteinase activates a detection enzyme, which in turn activates a detectable chromogenic substrate. Total metalloproteinase activity (endogenously active plus the activatable proenzyme) is measured by the addition of $\alpha$-aminophenylmercuric acetate, which artificially activates the inactive form of the metalloproteinase. The term "endogenous activity," therefore, refers to extractable bioactive metalloproteinase, and the term "total activity" refers to the detectable endogenous activity plus the artificially activated proenzyme. Based on preliminary data showing lower levels of endogenous metalloproteinase activity, we utilized the longer incubation protocol to increase sensitivity of the assay, as suggested by the manufacturer.

The levels of tissue inhibitor metalloproteinase-1 and -2 (TIMP-1 and -2) were quantified in the supernatants by enzymelinked immunosorbent assay (TIMP-1 and TIMP-2 Biotrak ELISA, Amersham Biosciences Corp). The activity values and inhibitor levels were standardized to total protein by dividing each by the total protein concentration assayed from the final supernatant.

\section{Statistical Analysis}

Results are displayed as mean values \pm standard error of the mean (SEM). Differences in means between groups were tested using the unpaired Student $t$ test. Satterthwaite's approximation was used when there was evidence of unequal variance. Fisher exact test was used to compare clinical variables between groups.

\section{Results}

By histologic examination all specimens showed some degree of cystic medial degeneration with fragmentation of elastic fibers. The presence of cystic medial necrosis was 




Figure 1. The endogenous activity of matrix metalloproteinase-2 in aneurysm walls of patients with bicuspid and tricuspid aortic valves (mean values \pm SEM, standardized to total protein). MMP-2, Matrix metalloproteinase-2.

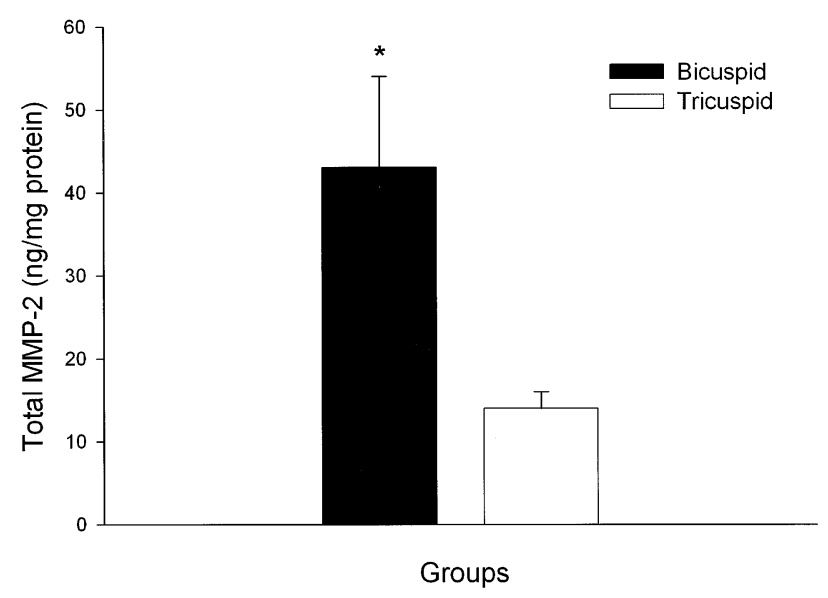

Figure 2. The total activity of matrix metalloproteinase-2 in aneurysm walls of patients with bicuspid and tricuspid aortic valves (mean values $\pm S E M$, standardized to total protein; ${ }^{*} \boldsymbol{P}=$ .02, Student $t$ test). MMP-2, Matrix metalloproteinase-2.

variable. No specimen showed histologic evidence of atheroma. No important differences were seen between the groups with regard to age, aneurysm size, gender, history of any valvular dysfunction, smoking, associated coronary artery disease, hypertension, or use of beta-blockers, calcium channel blockers, or angiotensin-converting enzyme inhibitors (Table 1). However, a trend was noted toward younger age in the bicuspid group. The tricuspid group had a higher incidence of aortic insufficiency when compared with the bicuspid group (67\% vs $25 \%$, Fisher exact test, $P=.05$ ).

Quantitative activity analysis of aneurysmal tissues showed that the endogenous activity of matrix metalloproteinase-2 was greater in the bicuspid group, but this did not reach statistical significance $(0.84 \pm 0.24 \mathrm{ng} / \mathrm{mg}$ protein vs
TABLE 1. Patient demographics

\begin{tabular}{lccr}
\hline & $\begin{array}{c}\text { Bicuspid valve, } \\
\mathbf{n}=\mathbf{1 6}(\%)\end{array}$ & $\begin{array}{c}\text { Tricuspid valve, } \\
\mathbf{n}=\mathbf{1 2}(\%)\end{array}$ & $\boldsymbol{P}$ value \\
\hline Age (mean, y) & $54.7 \pm 6.2$ & $63.9 \pm 10.1$ & .09 \\
Size (mean, cm) & $5.4 \pm 0.3$ & $5.7 \pm 0.5$ & .23 \\
Sex (male) & $14(88)$ & $11(92)$ & 1.00 \\
Hypertension & $10(63)$ & $9(75)$ & .69 \\
Aortic insufficiency & $4(25)$ & $8(67)$ & .05 \\
Aortic stenosis & $8(50)$ & $2(17)$ & .11 \\
Any valve dysfx. & $12(75)$ & $10(83)$ & .67 \\
Hyperlipidemia & $6(38)$ & $3(25)$ & .69 \\
Tobacco use & $7(44)$ & $4(33)$ & .70 \\
CAD & $8(50)$ & $4(33)$ & .46 \\
$\beta$-blocker & $9(56)$ & $5(42)$ & 1.00 \\
Ca ${ }^{+2}$ channel blocker & $1(6)$ & $0(0)$ & 1.00 \\
ACE inhibitor & $5(31)$ & $7(58)$ & .25 \\
\hline
\end{tabular}

Any valve dysfx. Any aortic valvular dysfunction, including both insufficiency and stenosis; $C A D$, coronary artery disease; $\beta$-blocker, beta blocker; $A C E$, angiotensin-converting enzyme.

$0.46 \pm 0.06 \mathrm{ng} / \mathrm{mg}$ protein; $t$ test, $P=.18$; Figure 1$)$. The total matrix metalloproteinase-2 activity was also greater in the walls of aneurysms associated with bicuspid aortic valves compared with tricuspid valves $(43 \pm 11 \mathrm{ng} / \mathrm{mg}$ protein vs $14 \pm 2 \mathrm{ng} / \mathrm{mg}$ protein; $t$ test, $P=.02$; Figure 2 ).

No meaningful difference was found in the endogenous activity of matrix metalloproteinase- 9 between the 2 groups (bicuspid: $0.31 \pm 0.2 \mathrm{ng} / \mathrm{mg}$ protein vs tricuspid: $0.11 \pm$ $0.06 \mathrm{ng} / \mathrm{mg}$ protein; $t$ test, $P>.20$; Figure 3 ). Aneurysms associated with bicuspid aortic valves, however, had greater total matrix metalloproteinase-9 activity when compared with aneurysms associated with tricuspid aortic valves (4.0 $\pm 0.9 \mathrm{ng} / \mathrm{mg}$ protein vs $1.5 \pm 0.35 \mathrm{ng} / \mathrm{mg}$ protein; $t$ test, $P$ $=.02$; Figure 4).

No meaningful differences were noted in the levels of tissue inhibitors- 1 and -2 between groups ( $t$ test, $P>.20$ ). Tissue inhibitor- 1 levels were $156 \pm 26 \mathrm{ng} / \mathrm{mg}$ protein in the bicuspid group and $172 \pm 35 \mathrm{ng} / \mathrm{mg}$ protein in the tricuspid group. Levels of tissue inhibitor- 2 were $22 \pm 5$ $\mathrm{ng} / \mathrm{mg}$ protein in the bicuspid group and $21 \pm 3 \mathrm{ng} / \mathrm{mg}$ protein in the tricuspid group (Figure 5).

\section{Discussion}

This study lends support to recent preliminary findings by others $^{19}$ that link an intrinsic biochemical abnormality within the walls of proximal thoracic aneurysms of patients with bicuspid aortic valves to previously reported clinical and histologic structural abnormalities. Specifically, the diminished distensibility, increased stiffness, dilatation, and fragmentation of elastic components within the aortic wall of patients with bicuspid aortic valves may be associated with the increased expression of matrix-degrading proteases.

Matrix degrading enzymes, metalloproteinase-2 and -9 , have been associated with the formation of abdominal aortic 


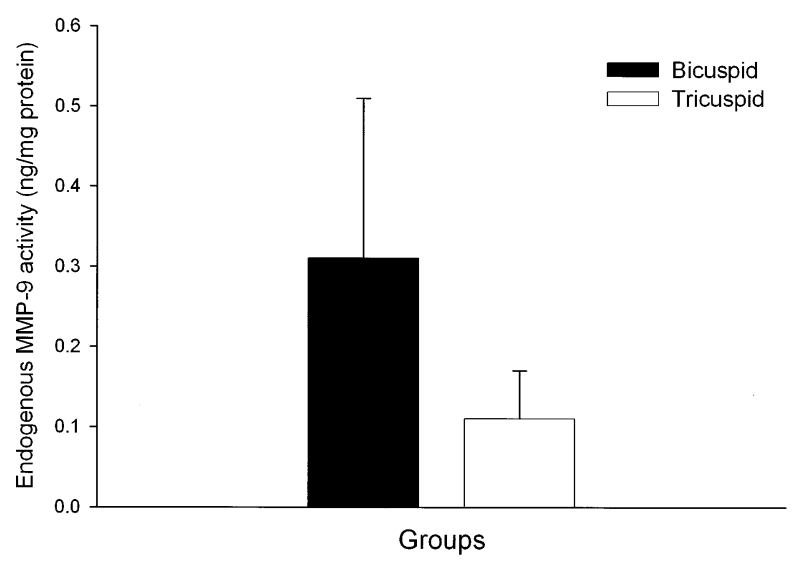

Figure 3. The endogenous activity of matrix metalloproteinase-9 in aneurysm walls of patients with bicuspid and tricuspid aortic valves (mean values \pm SEM, standardized to total protein). MMP-9, Matrix metalloproteinase-9.

aneurysms. ${ }^{13}$ Matrix metalloproteinase-9 is thought to be the most prominent protease associated with the formation of abdominal aortic aneurysms because of its link to the inflammatory infiltrate associated with these aneurysms. ${ }^{20}$ The vast majority of abdominal aortic aneurysms are atherosclerotic in origin, and their walls contain atheroma associated with an inflammatory cell infiltrate, including the tissue macrophage. Tissue macrophages are the major source of synthesis and secretion of matrix metalloproteinase-9. ${ }^{9}$ In a previous study, the walls of thoracic aortic aneurysms of atherosclerotic origin were found to contain significantly higher matrix metalloproteinase-9 activity when compared with nonatherosclerotic degenerative thoracic aneurysms and age-matched controls. ${ }^{16}$

The present study sought to quantitate the activity of matrix metalloproteinases and levels of their inhibitors in thoracic aortic aneurysms associated with bicuspid aortic valves. Because aneurysms associated with bicuspid aortic valves are degenerative in nature, ${ }^{6,7}$ they were compared with degenerative aneurysms associated with tricuspid aortic valves. Patients in both groups with documented atherosclerotic changes within the aortic wall were excluded from the study to eliminate the contribution of the inflammatory cell infiltrate. This should allow a more accurate analysis of the contribution of the intrinsic cellular subtypes, such as the smooth muscle cell and endothelial cell, to matrix metalloproteinase metabolism in these patients. The smooth muscle cell is a major source of the synthesis and secretion of metalloproteinase-2, TIMP-1, and TIMP-2 within the aortic wall, although it also has the capability to synthesize metalloproteinase-9. ${ }^{10}$

Because the proximal thoracic aortas of patients with bicuspid valves have abnormal elastic properties, which are present even before aneurysmal dilatation, it was hypothe-

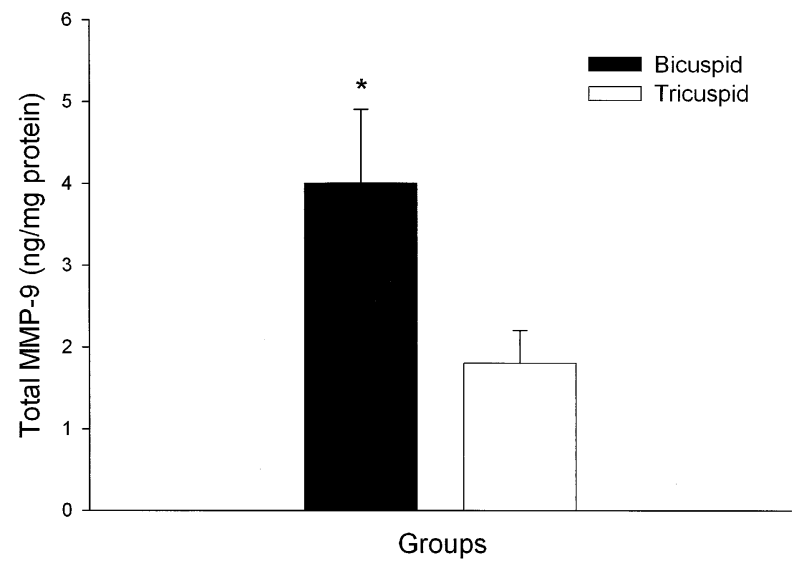

Figure 4. The total activity of matrix metalloproteinase-9 in aneurysm walls of patients with bicuspid and tricuspid aortic valves (mean values $\pm S E M$, standardized to total protein; ${ }^{*} P=$ .02 , Satterthwaite's $t$ test). MMP-9, Matrix metalloproteinase-9.

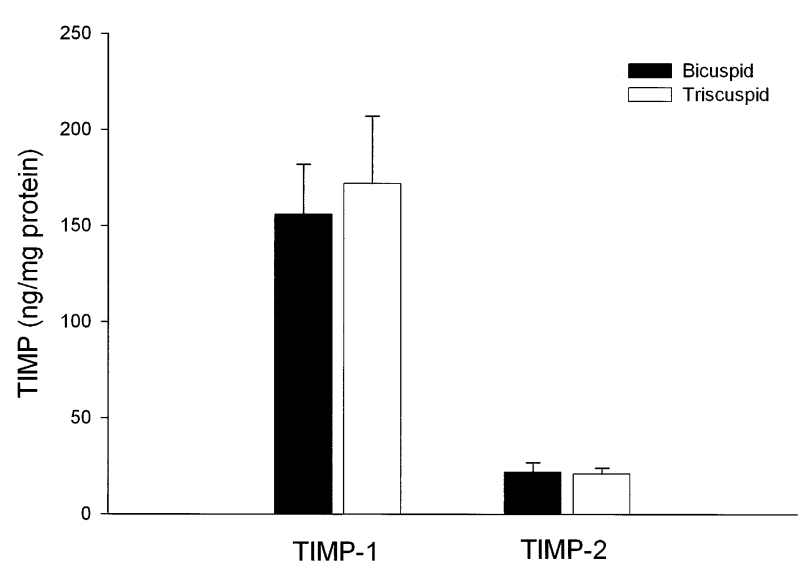

Figure 5. The levels of tissue inhibitor of matrix metalloproteinase in aneurysm walls of patients with bicuspid and tricuspid aortic valves (mean values $\pm S E M$, standardized to total protein). TIMP-1, Tissue inhibitor of matrix metalloproteinase-1; TIMP-2, tissue inhibitor of matrix metalloproteinase-2.

sized that aneurysms associated with bicuspid valves would have an increased activity of the elastin-degrading metalloproteinases when compared with aneurysms from patients with tricuspid aortic valves. There are 23 known matrix metalloproteinases expressed in human tissue. ${ }^{10}$ Matrix metalloproteinase- 2 and -9 were chosen for analysis in this study because of their known elastolytic properties ${ }^{21}$ and because of their known association with the formation of abdominal aortic aneurysms.

These data show that the potential for increased activity of matrix metalloproteinase- 2 and -9 are greater in the walls of aortic aneurysms associated with bicuspid aortic valves when compared with aneurysms from patients with tricus- 
pid valves. Although there were no significant differences between groups in regard to the presence of the bioactive species, there were significantly greater concentrations of the potentially inducible proenzyme form of both matrix metalloproteinase-2 and -9 . This suggests that the previously documented abnormal elastic properties and the increased risk for aneurysm formation in patients with bicuspid aortic valves may reflect the increased activity of these matrix degrading proteins within the aortic wall.

This evidence, however, does not negate the role that these proteases may play in the formation of proximal thoracic aneurysms in patients with tricuspid valves. What it may suggest, however, is that patients with bicuspid aortic valves have a predisposition to abnormal matrix metalloproteinase metabolism and may be more susceptible to aneurysmal dilatation when exposed to other known risk factors. Several risk factors for aneurysmal dilatation, including hypertension, are known to induce the expression of matrix metalloproteinases. ${ }^{9,22}$

Investigations into the mechanisms causing structural abnormalities in the aortas of patients with bicuspid aortic valves have found an increased rate of smooth muscle cell apoptosis, even in the absence of aneurysmal dilatation. ${ }^{8}$ Similar findings have been noted in abdominal aortic aneurysms. ${ }^{23,24}$ Interestingly, several of the tissue inhibitors of metalloproteinases, 4 of which have been identified in vertebrates ${ }^{10}$ have been shown to inhibit smooth muscle cell apoptosis. Both tissue inhibitor-1 and -2 have antiapoptotic properties. ${ }^{25,26}$ Overexpression of tissue inhibitor-1 in a rat model of aortic aneurysm prevented degeneration and rupture. ${ }^{27}$

This current study found no differences in the levels of tissue inhibitor- 1 and -2 in the walls of aneurysms from the 2 groups. Interestingly, the levels of tissue inhibitor- 1 found in this study were over twofold lower, and tissue inhibitor-2 was over fivefold lower, than values obtained from agematched aortas of patients undergoing coronary artery bypass grafting at this institution (unpublished data). Therefore, the ratio of metalloproteinases to their inhibitors may play an important role in aneurysm formation in both the bicuspid and tricuspid groups and requires further study. ${ }^{9}$ Because we found no differences between groups relative to the levels of tissue inhibitor, selective levels of tissue activators of the proenzyme forms may be more important in aneurysm generation between the 2 groups; this also requires further study.

A transition from a contractile to a synthetic phenotype in the smooth muscle cells may be more important in aneurysm formation than cellular loss or apoptosis. Smooth muscle cells cultured from abdominal aortic aneurysm specimens have been shown to produce significantly greater levels of matrix metalloproteinase- 2 and -9 when compared with controls. ${ }^{28,29}$ Lesaukaite and colleagues ${ }^{15}$ found in- creased concentrations of matrix metalloproteinase-1, -2 , and -9 in the walls of thoracic aortic aneurysms in the absence of significant smooth muscle cell loss. They proposed that mechanical forces, such as hypertension, could cause changes in intracellular contacts between smooth muscle cells, which may be responsible for this phenotypic conversion.

Genotype abnormalities can directly cause thoracic aortic aneurysms, as with the defect in the fibrillin-1 gene in patients with Marfan syndrome. In a mouse model of Marfan syndrome, a mutation in the gene encoding fibrillin changed smooth muscle cells from a contractile to a synthetic phenotype. This was associated with an increased production of matrix metalloproteinase- 9 within the aortic wall and subsequent elastin fragmentation. ${ }^{30}$ Segura and colleagues ${ }^{17}$ have documented an up-regulation of the synthesis of matrix metalloproteinase-2 and -9 in Marfan patients with thoracic aortic aneurysms. Fedak and colleagues $^{19}$ have suggested a link between fibrillin-1 deficiency and increased matrix metalloproteinase- 2 activity in the proximal aorta of patients with bicuspid aortic valves.

One could postulate that nonatherosclerotic degenerative aneurysms of the proximal thoracic aorta may form after the induction of a phenotypic change in the smooth muscle cell, such as exposure to long-standing hypertension. Patients with bicuspid aortic valves may have a greater predisposition to this change in phenotype by a preexisting genetic defect. The timing and onset of these changes may be earlier, and with greater severity, in the aortic wall associated with a bicuspid aortic valve, offering 1 explanation as to why there are higher activities of matrix metalloproteinase-2 and -9 in these patients. Recent work by the group at Washington University in St Louis supports this hypothesis. They documented differing patterns of gene expression in the walls of aneurysms from patients with bicuspid aortic valves when compared with those from patients with tricuspid aortic valves. ${ }^{31}$

\section{Limitations}

This study is purely observational in scope and was performed with a limited number of patients and tissue samples. Tissue was obtained and analyzed at an isolated point in time in a continuum of disease progression. As such, a cause-and-effect relationship between metalloproteinase expression and aneurysmal dilatation cannot definitively be concluded. In addition, these data cannot be interpreted as a generalization that all patients with bicuspid aortic valves have an intrinsic abnormality in matrix metalloproteinase metabolism. The patients in this study were selected because they already had aneurysmal dilatation. Many individuals with bicuspid aortic valves do not develop aneurysmal dilatation, just as others never develop a clinical problem with their structurally abnormal valve. 
This study only measured isolated metalloproteinase activity ex vivo. Bioactivity assays were not utilized. Also, total metalloproteinase activity was measured after artificial induction and does not represent the potential myriad of constraints on activation or inhibition in vivo.

Finally, this study was not designed to correlate metalloproteinase activity and inhibitor levels with the grade or degree of histological changes. Perhaps a stronger argument for the association of increased metalloproteinase activity with aneurysmal dilatation in patients with bicuspid valves could be made if this study had sought to show a greater degree of elastin fragmentation in these patients when compared with the tricuspid group.

\section{Conclusion}

An increased expression of matrix metalloproteinase-2 and -9 activity exists in nonatherosclerotic proximal thoracic aortic aneurysms of patients with bicuspid aortic valves when compared with proximal thoracic aneurysms of patients with tricuspid aortic valves. These alterations in 2 prominent extracellular matrix proteases may help explain the structural and histologic changes, mostly related to elastin metabolism, seen in patients with bicuspid aortic valves. A genetic alteration in matrix metalloproteinase metabolism may explain the susceptibility and earlier onset of aortic pathology seen in some patients with bicuspid aortic valves.

\section{References}

1. Nkomo VT, Eriquez-Sarano M, Ammash NM, Melton LJ 3rd, Bailey KR, Desjardins V, et al. Bicuspid aortic valve associated with aortic dilatation: a community-based study. Arterioscler Thromb Vasc Biol. 2003;23:351-6.

2. Nistri S, Sorbo MD, Marin M, Palisi M, Scognamiglio R, Thiene G. Aortic root dilatation in young men with normally functioning bicuspid aortic valves. Heart. 1999;82:19-22.

3. Keane MG, Wiegers SE, Plappert T, Pochettino A, Bavaria JE, Sutton MG. Bicuspid aortic valves are associated with aortic dilatation out of proportion to coexistent valvular lesions. Circulation. 2000;102: III35-9.

4. Nistri S, Sorbo MD, Basso C, Thiene G. Bicuspid aortic valve: abnormal aortic elastic properties. J Heart Valve Dis. 2002;11:369-73.

5. Niwa K, Perloff JK, Bhuta SM, Laks H, Drinkwater DC, Child JS, et al. Structural abnormalities of great arterial walls in congenital heart disease: light and electron microscopic analyses. Circulation. 2001; 103:393-400.

6. de Sa M, Moshkovitz Y, Butany J, David TE. Histological abnormalities of the ascending aorta and pulmonary trunk in patients with bicuspid aortic valve disease: clinical relevance to the Ross procedure. J Thorac Cardiovasc Surg. 1999;118:588-96.

7. Bauer M, Pasic M, Meyer R, Goetze N, Bauer U, Siniawski H, et al. Morphometric analysis of aortic media in patients with bicuspid and tricuspid aortic valve. Ann Thorac Surg. 2002;74:58-62.

8. Bonderman D, Gharehbaghi-Schnell E, Wollenek G, Mauer G, Baumgartner H, Lang IM. Mechanisms underlying aortic dilation in congenital aortic valve malformation. Circulation. 1999;99:2138-43.

9. Galis ZS, Khatri JJ. Matrix metalloproteinases in vascular remodeling and atherogenesis: the good, the bad, and the ugly. Circ Res. 2002; 90:251-62.

10. Visse R, Nagase H. Matrix metalloproteinases an tissue inhibitors of metalloproteinases: structure, function, and biochemistry. Circ Res. 2003;92:827-39.

11. Longo GW, Xiong W, Greiner TC, Zhao Y, Fiotii N, Baxter BT.
Matrix metalloproteinases 2 and 9 work in concert to produce aortic aneurysms. J Clin Invest. 2002;110:625-32.

12. Elmore JR, Keister BF, Franklin DP, Youkey JR, Carey DJ. Expression of matrix metalloproteinases and TIMPs in human abdominal aortic aneurysms. Ann Vasc Surg. 1998;12:221-8.

13. Freestone T, Turner RJ, Coady A, Higman DJ, Greenhalgh RM, Powell JT. Inflammation and matrix metalloproteinases in the enlarging abdominal aortic aneurysm. Arterioscler Thromb Vasc Biol. 1995; 15:1145-51.

14. White JV, Haas K, Phillips S, Comerota AJ. Adventitial elastolysis is a primary event in aneurysm formation. J Vasc Surg. 1993;17:371-80.

15. Lesauskaite V, Tanganelli P, Sassi C, Neri E, Diciolla F, Ivanoviene L, et al. Smooth muscle cells of the media in the dilative pathology of ascending thoracic aorta: morphology, immunoreactivity for osteopontin, matrix metalloproteinases, and their inhibitors. Hum Pathol. 2001; 32:1003-11.

16. Fellinger E, Trombley L, Schmoker JD. Matrix metalloproteinase levels in thoracic aortic aneurysms [abstract]. J Am Coll Surg. 2002; 195:S101.

17. Segura AM, Luna RE, Horiba K, Stetler-Stevenson WG, McAlister HA, Willerson JT, et al. Immunohistochemistry of matrix metalloproteinases and their inhibitors in thoracic aortic valves of patients with Marfan's syndrome. Circulation. 1998;98:II331-8.

18. Vine N, Powell JT. Metalloproteinases in degenerative aortic disease. Clin Sci (Lond). 1991;81:233-9.

19. Fedak PWM, de Sa MP, Verma S, Nili N, Kazemian P, Butany J, et al. Vascular matrix remodeling in patients with bicuspid aortic valve malformations: implications for aortic dilatation. J Thorac Cardiovasc Surg. 2003;126:797-806.

20. McMillan WD, Tamarina NA, Cipollone M, Johnson DA, Parker MA, Pearce WH. Size matters. The relationship between MMP-9 expression and aortic diameter. Circulation. 1997;96:2228-32.

21. Shipley JM, Doyle GA, Fliszar CJ, Ye QZ, Johnson LL, Shapiro SD, et al. The structural basis for the elastolytic activity of the 92-kDa and 72-kDa gelatinases: role of the fibronectin type II-like repeats. J Biol Chem. 1996;271:4335-41.

22. Chesler N, Ku D, Galis ZS. Transmural pressure induces matrix-degrading activity in porcine arteries ex vivo. Am J Physiol. 1999;277:H2002-9.

23. Lopez-Candeles A, Holmes DR, Liao S, Scott MJ, Wickline SA, Thompson RW. Decreased vascular smooth muscle cell density in medial degeneration of human abdominal aortic aneurysms. Am J Pathol. 1997;150:993-1007.

24. Thompson RW, Liao S, Curci JA. Vascular smooth muscle cell apoptosis in abdominal aortic aneurysms. Coron Artery Dis. 1997;8:62331.

25. Valente P, Fassina G, Melchiori A, Cilli M, Vacca A, Onisto M, et al. TIMP-2 overexpression reduces invasion and angiogenesis and protects B16F10 melanoma cells from apoptosis. Int J Cancer. 1998;75: 246-53.

26. Guedez L, Courtemanch L, Stetler-Stevenson M. Tissue inhibitor of metalloproteinase (TIMP)-1 induces differentiation and an antiapoptotic phenotype in germinal center B cells. Blood. 1998;92:1342-9.

27. Allaire E, Forough R, Clowes M, Starcher B, Clowes AW. Local overexpression of TIMP-1 prevents aortic aneurysm degeneration and rupture in a rat model. $J$ Clin Invest. 1998;102:1413-20.

28. Patel MI, Melrose J, Ghosh P, Appleberg M. Increased synthesis of matrix metalloproteinases by aortic smooth muscle cells is implicated in the etiopathogenesis of abdominal aortic aneurysms. J Vasc Surg. 1996;24:82-92.

29. Crowther M, Goodall S, Jones JL, Bell PR, Thompson MM. Increased matrix metalloproteinase 2 expression in vascular smooth muscle cells cultured from abdominal aortic aneurysms. J Vasc Surg. 2000;32:57583.

30. Bunton TE, Biery NJ, Myers L, Gayraud B, Ramirez FR, Dietz HC. Phenotypic alteration of vascular smooth muscle cells precedes elastolysis in a mouse model of Marfan syndrome. Circ Res. 2001;88:3743.

31. Absi TS, Van Vicle-Chavez S, Sundt TM, Moon MR, Damiano RJ, Thompson RW. Gene expression in ascending aortic aneurysms associated with normal and bicuspid aortic valves [abstract]. Circulation. 2003;108(Suppl IV):480. 